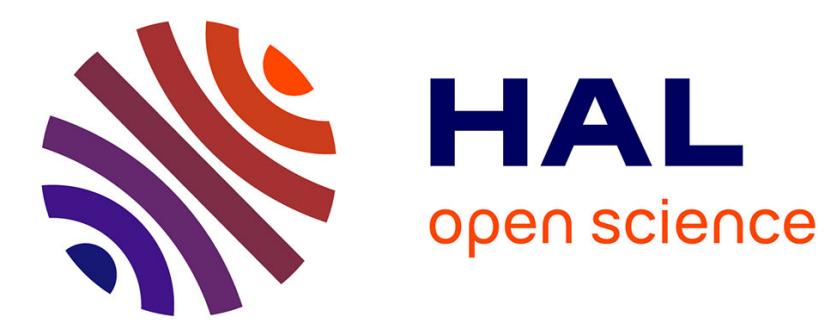

\title{
Signatures of the 1976-1977 Regime Shift in the North Pacific Revealed by Statistical Analysis
}

\author{
K. Giamalaki, C. Beaulieu, Davide Faranda, S. A. Henson, S. Josey, A. P. \\ Martin
}

\section{- To cite this version:}

K. Giamalaki, C. Beaulieu, Davide Faranda, S. A. Henson, S. Josey, et al.. Signatures of the 1976-1977 Regime Shift in the North Pacific Revealed by Statistical Analysis. Journal of Geophysical Research. Oceans, 2018, 123 (6), pp.4388-4397. 10.1029/2017JC013718 . hal-02334268

\section{HAL Id: hal-02334268 https://hal.science/hal-02334268}

Submitted on 1 Jul 2020

HAL is a multi-disciplinary open access archive for the deposit and dissemination of scientific research documents, whether they are published or not. The documents may come from teaching and research institutions in France or abroad, or from public or private research centers.
L'archive ouverte pluridisciplinaire HAL, est destinée au dépôt et à la diffusion de documents scientifiques de niveau recherche, publiés ou non, émanant des établissements d'enseignement et de recherche français ou étrangers, des laboratoires publics ou privés. 


\section{Journal of Geophysical Research: Oceans}

\section{RESEARCH ARTICLE Signatures of the 1976-1977 Regime Shift in the North Pacific 10.1029/2017JC013718 Revealed by Statistical Analysis}

Key Points:

-We show that an extremely deep and persistent Aleutian Low have contributed to trigger the major North Pacific regime shift in 1976-1977

- We show that abrupt changes in net heat flux occurred in the Kuroshio Extension and have helped to maintain the regime shift conditions - We use a novel statistical approach for an in-depth analysis of North Pacific sea level pressure extreme events and their relation to regime shifts

Supporting Information: - Supporting Information S1

Correspondence to:

K. Giamalaki,

ag2e13@soton.ac.uk

Citation:

Giamalaki, K., Beaulieu, C., Faranda, D., Henson, S. A., Josey, S. A., \&

Martin, A. P. (2018). Signatures of the 1976-1977 regime shift in the North Pacific revealed by statistical analysis. Journal of Geophysical Research: Oceans, 123, 4388-4397. https://doi. org/10.1029/2017JC013718

Received 18 DEC 2017 Accepted 10 MAY 2018 Accepted article online 25 MAY 2018 Published online 30 JUN 2018

\author{
K. Giamalaki1 (D), C. Beaulieu1,2 (D), D. Faranda3 (D), S. A. Henson 4 (D) S. A. Josey4, and A. P. Martin 4 (i)
}

${ }^{1}$ Ocean and Earth Science, University of Southampton, European Way, Southampton, UK, ${ }^{2}$ Ocean Sciences Department, University of California, Santa Cruz, CA, USA, ${ }^{3}$ Laboratoire des Sciences du Climat et de I'Environnement, LSCE/IPSL, CEACNRS-UVSQ, Université Paris-Saclay, Gif-sur-Yvette, France, ${ }^{4}$ National Oceanography Centre, European Way, Southampton, UK

\begin{abstract}
Regime shifts are abrupt changes in an ecosystem that may propagate through multiple trophic levels and have pronounced effects on the biotic and abiotic environment, potentially resulting in ecosystem reorganization. There are multiple mechanisms that could cause such abrupt events including natural and anthropogenic factors. In the North Pacific, a major shift in the physics of the system, including a sudden increase in sea surface temperature, was reported in 1977 with a prominent biological response in the lower trophic levels and subsequent effects on the fisheries and economy of the region. Here we investigate the statistics of physical processes that could have triggered and maintained the late 1970s shift. The hypothesis of an extreme sea level pressure event abruptly changing the oceanic conditions in winter 1976-1977, which was maintained by long-term changes in air-sea interaction processes, is tested. Using dynamical proxies, we show the occurrence of an extreme atmospheric event, specifically a persistent Aleutian Low during winter 1976-1977, which constitutes a substantial part of the triggering mechanism of the regime shift. Subsequent sudden changes in the net heat flux occurred in the western North Pacific, particularly in the Kuroshio Extension region, which contributed to the maintenance of the new regime.
\end{abstract}

\section{Introduction}

A marine ecosystem regime is defined as a persistent, equilibrium ocean state characterized by specific physical and biological conditions (Beamish et al., 2004). The transitions between different states are known as regime shifts and are typically described as abrupt changes that present high amplitude variability, propagate through multiple trophic levels and lead to ecosystem restructuring (Conversi et al., 2015; Lees et al., 2006). The main mechanisms suggested to drive these shifts include processes in the biotic and abiotic environment, as well as changes within the structure of the natural environment itself (deYoung et al., 2008). Multiple factors may also act synergistically to initiate and maintain a regime shift (Cury \& Shannon, 2004). Thus, identifying the mechanisms driving these sudden changes is a challenge due to the complexity of the ocean system and its multiple environmental forcings (deYoung et al., 2008; Lees et al., 2006).

A major shift occurred in the North Pacific in winter 1976-1977 (Hare \& Mantua, 2000). The complex internal and teleconnection dynamics of the North Pacific play a marked role in driving the physical properties of the basin, notably a significant cooling in the central North Pacific and warming in the eastern region. This sea surface temperature (SST) pattern is described as the positive phase of the leading mode of North Pacific variability, the Pacific Decadal Oscillation (PDO) (Mantua et al., 1997). The phase shifts of the PDO have been directly related to the major regime shifts of the North Pacific in 1925, 1940, and 1977 (Chavez et al., 2003; Mantua et al., 1997; Minobe, 1997; Zhang et al., 1997), leading to pronounced effects on the regional biology and fisheries (Schwing et al., 2010). PDO shifts are consistent with expected variability from the red noise (Rudnick \& Davis, 2003), where atmospheric noise combined with ocean thermodynamics determine the decadal climate variability and redden the oceanic memory (Pierce, 2001). The second leading mode of the North Pacific SST variability, described by the North Pacific Gyre Oscillation (NPGO), represents changes in physical and biological variables that also impact the regional biological dynamics (Di Lorenzo et al., 2008). Long-term changes and community reorganization have been reported in the whole North Pacific in response to the shift (Yatsu et al., 2008), in addition to the collapse of foraging fish 
populations and the rapid increase of ground fish and salmon populations in the Gulf of Alaska (Anderson \& Piatt, 1999; McGowan, 1998). Specifically, dramatic fluctuations of salmon abundance in the Gulf of Alaska have been linked to PDO-driven variability (Mantua et al., 1997). Biological time series in large marine systems as the North Pacific have the potential to exhibit regime shifts as a nonlinear response to physical forcing (Hsieh et al., 2005) or by linear tracking of the environment (Hsieh \& Ohman, 2006). Di Lorenzo and Ohman (2013) suggested that state transitions can also be described by cumulative integration of environmental and climate forcing.

The North Pacific atmospheric dynamics are characterized by two main sea level pressure (SLP) patterns: the Aleutian Low and the North Pacific High. The Aleutian Low is defined as a low atmospheric pressure system above the Aleutian Islands and the Gulf of Alaska that dominate the region during winter time (Wang et al., 2012). Changes in the intensity of the Aleutian Low are reflected in the North Pacific Index, which is calculated from the area-weighted sea level pressure over the North Pacific (Trenberth \& Hurrell, 1994). The North Pacific High is a high-pressure system located above the California region which is fully developed during summer (Kenyon, 1999).

A change in the North Pacific atmospheric pressure patterns, specifically a deepening of the Aleutian Low, has been suggested as the main mechanism to trigger the sudden change in the late 1970s (Hare \& Mantua, 2000). The Aleutian Low deepening was related to a switch from a negative to positive phase of the PDO (Mantua et al., 1997), which is linked to the El Niño Southern Oscillation (ENSO) (Newman et al., 2016). An intensification of the westerlies caused a negative wind stress curl, resulting in increased SST along the eastern coast and decreased SST in the central and western North Pacific (Latif \& Barnett, 1994; Miller et al., 1994), through enhanced surface heat fluxes and anomalous Rossby waves (Mantua \& Hare, 2002; Qiu et al., 2007). Modeling studies have also proposed that the maintenance of these conditions was mainly due to changes in the heat budget throughout the whole extent of the ocean basin, including changes in terms such as horizontal advection, mixing/entrainment, and air-sea heat fluxes (Miller et al., 1994). Previous studies suggested that a positive phase of PDO (deep Aleutian Low) is related to negative phase of Kuroshio Extension dynamical state, and vice versa (Qiu et al., 2016). Qiu (2003) showed that the strength of the Kuroshio Extension jet is related to the sea surface height anomalies that originate from the eastern North Pacific as a result of wind forcing. Further, a coupled oceanatmosphere modeling scenario suggested that warm SST anomalies in the eastern North Pacific cause negative local sea surface height anomalies toward the west, resulting in alterations in the Kuroshio Extension SST (Qiu et al., 2007). The PDO phases have been recently linked to the Kuroshio Extension phases affecting the strength of the jet, the sea surface height, and the SST of the extension region (Qiu et al., 2016). On the other hand, modeling studies showed that the Kuroshio Extension circulation variability is part of the forcing mechanisms of the PDO (Schneider \& Cornuelle, 2005). A positive phase of the Kuroshio Extension (warm SST anomalies) presents prominent atmospheric responses due to increased heat loss from the ocean, affecting the atmospheric circulation of the whole North Pacific (Révelard et al., 2016). Alternative hypotheses regarding the trigger and maintenance mechanisms of the regime shift have also suggested that tropical ENSO teleconnections (Graham, 1994; Nitta \& Yamada, 1989) as well as variations of the tropical Indo-Pacific climate (Deser et al., 2004), may have caused these SLP and subsequently SST anomalies.

This study aims to statistically identify the unique signatures that are associated with the initiation and persistence of the conditions for the major North Pacific regime shift in 1976-1977. Although the late 1970s regime shift has been widely studied, the limited understanding of the dynamics of regime shifts, specifically in the case of multiple driving forcings in complex systems such as the North Pacific (deYoung et al., 2008), call for further scrutiny. Here we use a combination of extreme value analysis on dynamical proxies and change-point detection to reveal new insights. First, we test the hypothesis that an extreme atmospheric event, specifically the deepening of the winter Aleutian Low, was the main triggering factor of the unusual oceanic conditions that resulted in a new environmental state of the North Pacific region (Miller et al., 1994; Yasunaka \& Hanawa, 2002). To test this hypothesis, we use dynamical proxies to identify extreme SLP patterns in the North Pacific region. Second, we investigate through change-point analysis whether changes in the air-sea interaction factors, particularly in heat budget terms, helped to maintain these altered oceanic conditions (Miller et al., 1994) and allowed the new regime to persist for multiple years. 


\section{Methodology}

\subsection{Data}

The North Pacific region from $20^{\circ} \mathrm{N}$ to $60^{\circ} \mathrm{N}$ and $100^{\circ} \mathrm{E}$ to $90^{\circ} \mathrm{W}$ was the focus of this study. Daily sea level pressure (SLP) and net heat flux data were obtained from the National Center for Environmental Prediction/ National Center for Atmospheric Research (NCEP/NCAR) reanalysis project (Kalnay et al., 1996) with spatial resolution of $2.5^{\circ} \times 2.5^{\circ}$ from 1948 to present. Net heat flux was calculated by summing the latent, sensible, net long wave flux, and net solar flux components. As such, negative values of net heat flux represent heat loss from the ocean to the atmosphere, and vice versa. The North Pacific Index (NPI), used here for the SLP pattern comparison of the dynamical analysis results, was obtained from the "The Climate Data Guide: North Pacific" (Hurrell et al., 2016). The NPI is the area-weighted SLP over the region and is defined as a measure of the atmospheric variations of the North Pacific on interannual to decadal time-scales (Trenberth \& Hurrell, 1994).

\subsection{Dynamical Proxies}

In order to identify extreme atmospheric events that may have triggered the regime shift in 1976-1977, we use an approach combining extreme value theory and dynamical system analysis proposed by Faranda et al. (2017). This method has the advantage of providing a natural way to detect extremes in the time series and can be used to understand features of physical systems (Faranda et al., 2011, 2017). In this setting, we consider the atmospheric flows as chaotic and settled on an attractor, which is defined as a set of states that the system approaches repeatedly. Mathematically, attractors are characterized by their instantaneous properties, termed as the instantaneous dimension, $\mathrm{d}(\zeta)$, and the inverse-persistence, $\theta(\zeta)$, where $\zeta$ represents the state of the attractor. They measure the number of patterns similar to the current one $(\zeta)$ that occur in the time series and the persistence of each one of those patterns. A high instantaneous dimension indicates that the dynamics are highly unpredictable since the system can move into any one of $d$ possible configurations at a given time, whereas a low instantaneous dimension indicates that the system tends to follow simple dynamics. Further, $\theta(\zeta)$ is defined as the inverse of persistence time of each pattern of the field. Thus, the lower the $\theta(\zeta)$, the more persistent the state $\zeta$ of the attractor and the more likely that the previous and future states will appear like state $\zeta$. The approach is based on fitting a generalized Pareto distribution to the exceedances above a specified threshold, following the Peak Over Threshold method (Pickands, 1975). Hence, we define the extremes in daily sea level pressure instantaneous properties as the 0.02 and 0.98 quantiles, i.e., cutoffs separating the $2 \%$ smallest and largest values in the time series, respectively. The results are found to be insensitive to the choice of the quantiles for the extremes threshold selection (e.g., 0.05 and 0.95 quantiles, supporting information Figures S1 and S2). Additional details of the approach are presented in supporting information.

\subsection{Regime Shift Analysis}

Empirical Orthogonal Functions (EOF) are used to explore the spatial patterns and temporal variability of net heat flux time series in the North Pacific. Additionally, change-point detection is used to investigate the presence (or absence) of an abrupt change in the net heat flux in the North Pacific. Specifically, we use the "environmental time series change-point detection" approach "EnvCpt," (Killick et al., 2018). We use this method as it enables regime shifts (characterized by abrupt changes in the mean) to be distinguished from long-term trends and red noise. Red noise represents the memory of the random atmospheric forcing (i.e., white-noise) in the ocean (Overland et al., 2006). In order to detect temporal and spatial abrupt changes in the North Pacific, the EnvCpt approach is primarily applied here to monthly net heat flux data with a minimum segment length of 10 years of data to ensure enough observations are used to estimate abrupt changes. Additional details of the approach are presented in supporting information.

Novel aspects of this study include the application of the dynamical system analysis and change-point detection to investigate extreme events in the North Pacific SLP and abrupt changes in net heat flux for the first time, to the extent of our knowledge. The combination of techniques used here reveal the mechanisms leading to regime shifts, with the main requirements being the availability of data and the nature of the distribution of the tail observations of the time series. Specifically, the dynamical system analysis requires a sufficient series of data (for more details see Faranda et al., 2011) and that the tails of the distribution of the observations follow a generalized Pareto distribution (see supporting information). The EnvCpt method assumes that the time series behaves as a combination of a constant mean or a long-term trend, with a 
background of white-noise or a first-order autocorrelation process (AR(1)), with the possibility of abrupt changes in all possible model configurations.

\section{Results}

\subsection{North Pacific Sea Level Pressure Extremes}

The SLP patterns that correspond to extreme values of instantaneous dimension and inverse-persistence are presented in Figure 1, together with the related phases of the North Pacific Index (Figure 1a). When the $\mathrm{NPI}$ is in its negative phase, the instantaneous dimension tends to be low, and the atmospheric configuration of SLP anomalies reveals an extremely deep Aleutian Low pattern (Figure 1b). On the other hand, extreme high inverse-persistence is associated with North Pacific atmospheric blocking patterns (Figure 1c), which are defined as strong high-pressure systems splitting the westerly flow into two branches. The instantaneous dimension extreme high corresponds to a spring transition pattern (Figure 1d). Finally, when the inverse-persistence is extremely low, the atmospheric configuration corresponds to a strong North Pacific High signal (Figure 1e).

North Pacific SLP patterns present strong seasonality with significant differences between summer and winter (Johnson \& Feldstein, 2010). Since the instantaneous properties are expected to have a direct correspondence to large-scale atmospheric patterns, a similar seasonal cycle would be expected to emerge in the results. Indeed, the low instantaneous dimension quantile that revealed the extreme Aleutian Low, occurred most frequently during winter (Figure $2 \mathrm{~b}$ ). The low inverse-persistence feature occurs most frequently in the summer and represents the North Pacific High atmospheric pattern (Figure 2e). High inversepersistence and instantaneous dimension are observed during spring and autumn (Figures $2 \mathrm{c}$ and $2 \mathrm{~d}$ ), when the atmospheric blocking and spring transition patterns develop in the region.

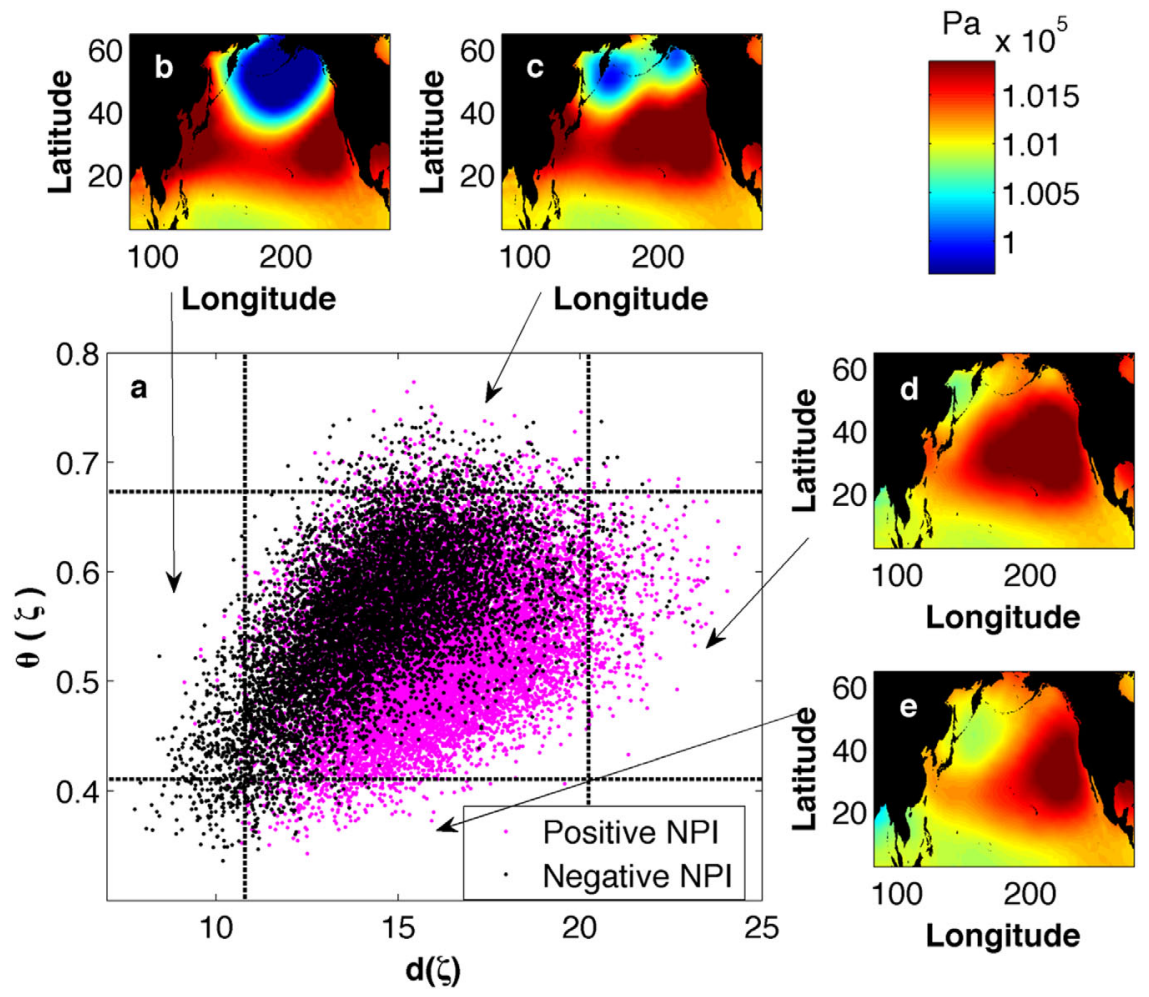

Figure 1. Daily instantaneous properties of the North Pacific daily sea level pressure (a) inverse-persistence $(\theta(\zeta))$ and instantaneous dimension $(\mathrm{d}(\zeta))$ according to the corresponding North Pacific Index (NPI) phase. Dashed lines define the 0.02 and 0.98 quantiles of $d(\zeta)$ and $\theta(\zeta)$. (b-e) Average daily sea level pressure patterns corresponding to the inversepersistence and instantaneous dimension extremes: (b) instantaneous dimension extreme low (Aleutian Low), (c) inversepersistence extreme high (atmospheric blocking pattern), (d) instantaneous dimension extreme high (spring transition pattern), and (e) inverse-persistence extreme low (North Pacific High). 


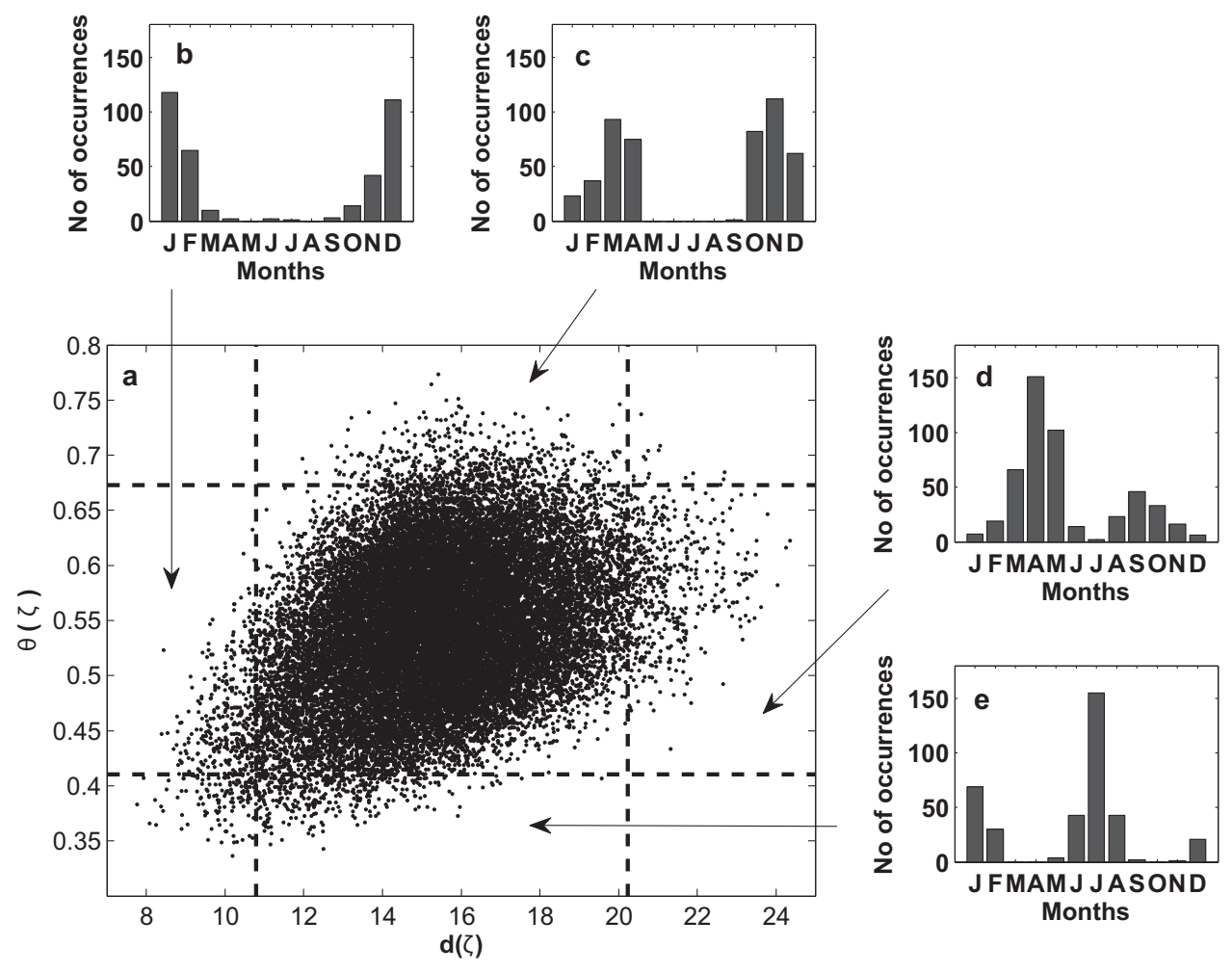

Figure 2. (a) Daily values of sea level pressure instantaneous properties. Number of days for each month corresponding to (b) instantaneous dimension extreme low, (c) inverse-persistence extreme high, (d) instantaneous dimension extreme high, and (e) inverse-persistence extreme low.

The number of days of each year in which the instantaneous dimension is in its extreme low state (2\% quantile), i.e., the pattern corresponding to the extreme Aleutian Low, is presented in Figure 3a. The year with the highest number of days with this extreme pattern is 1977 (16 days), more than double the average (5.3 days). Furthermore, we identified in which months the instantaneous dimension extreme low was pre-
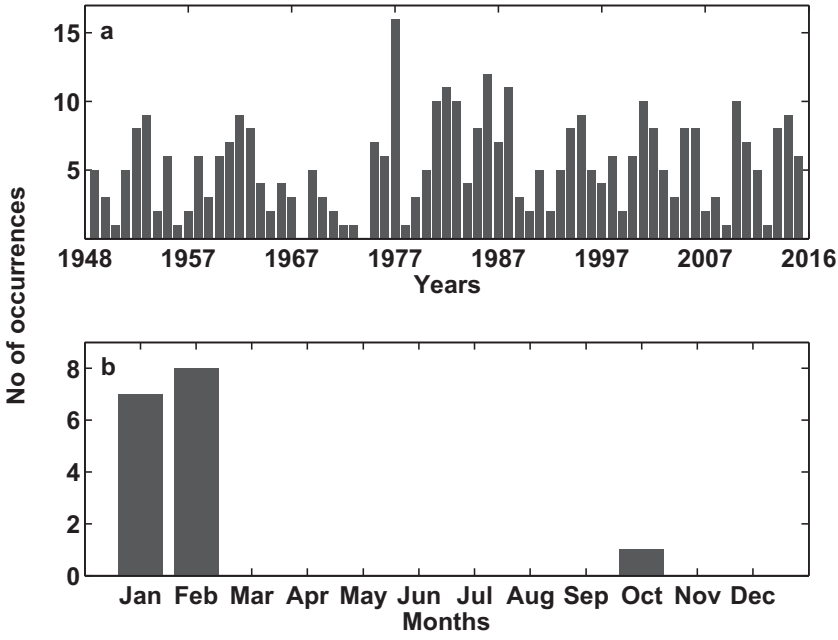

Figure 3. (a) Number of days in each year in which the sea level pressure instantaneous dimension extreme low $(\mathrm{d}(\zeta))$ state occurs ( $2 \%$ quantile; corresponding to the extreme Aleutian Low pattern). The maximum number of extremes occurred in 1977. (b) Number of extreme low sea level pressure instantaneous dimension $(\mathrm{d}(\zeta))$ occurrences per month in 1977. sent. The total percentage of days falling within winter months (December-January-February) throughout the whole study period was $80 \%$. Specifically for $1976-1977,91 \%$ of the instantaneous dimension extreme low states occur during winter (January and February; Figure 3b).

\subsection{Abrupt Changes in Net Heat Flux}

The first EOF of net heat flux reveals a pattern around the Kuroshio Extension region, explaining $22 \%$ of the variability (Figure $4 a$ ). Figure $4 \mathrm{~b}$ presents the temporal evolution of the first EOF, showing how the pattern varies in time. A sudden change in the temporal evolution of the first EOF around the late 1970s is suggested. This shift indicates a potential sudden and sustained change in net heat flux that we investigate further with change-point analysis.

Change-point analysis was applied on the first EOF of net heat flux and revealed a sudden step around the year 1979 (supporting information Figure S4). We identified the best fit according to the Akaike Information Criterion (AIC), which assesses performance based on a good fit and robustness of the statistical model (Akaike, 1973). The lowest AIC was the linear trend with a change-point in 1979 and firstorder autocorrelated errors (Figure 4c). 

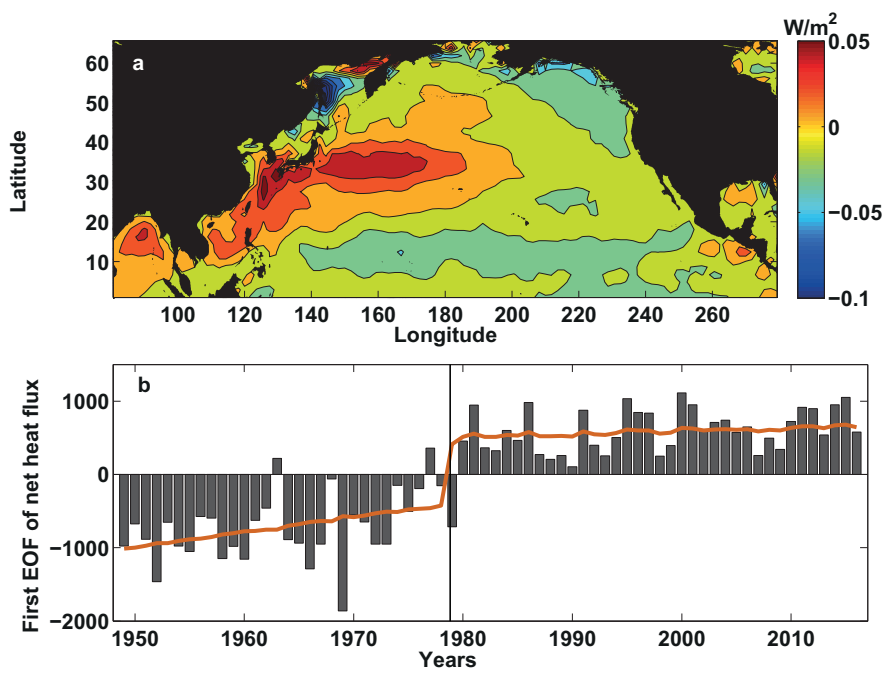

Figure 4. (a) First Empirical Orthogonal Function of net heat flux in the North Pacific, and (b) its temporal evolution (bars) with the corresponding EnvCpt best fit (trend with a change-point and autocorrelation; all tested fits are presented in supporting information Figure S4). The vertical bar indicates the timing of the shift in 1979.
In order to confirm the temporal but also spatial variations in heat exchange, a pixel-wise change-point analysis was applied on monthly data. Change-points were detected mainly in the western Pacific, where the Kuroshio Extension region and part of the tropical Pacific presented coherent changes around the year 1977 (Figure 5). Since the results of both the EOF and change-point methods presented spatial consistency, further emphasis was given to the Kuroshio Extension region where numerous change-points were detected around 1976-1978 (Figure 5). This suggests that the sudden change in net heat flux is regional and consistent with the hypothesis that the maintenance of the oceanic conditions causing the regime shift was due to deviations in heat budget terms (Miller et al., 1994), specifically increased heat flux into the ocean concentrated in the Kuroshio Extension region.

\section{Discussion}

The findings of our analysis provide evidence that an extreme Aleutian Low occurred in winter of 1976-1977 (Figure 1a), and that it was the strongest and most persistent such event throughout the entire study period. Typically, the Aleutian Low presents its highest intensity during boreal winter (Rienecker \& Ehret, 1988; Wang et al., 2012). However, this atmospheric configuration in its extreme phase was more persistent than usual during the winter of 1976-1977, when it was present for more than double the average number of days (Figure 3). This indicates a particularly strong and persistent event with the potential to alter the oceanic physical parameters in a striking way. An extreme deepening of the Aleutian Low increases the westerly winds strength and consequently decreases the SST in the central North Pacific as a response to increased surface heat fluxes. Similarly, the extreme Aleutian Low also increases the southerly winds, causing reduced heat losses and eastward Ekman currents advecting warmer SST toward the east coast (Miller et al., 1994; Miller \& Schneider, 2000). An extensively accepted hypothesis for the mechanism causing the regime shift in 1976-1977 is that an unusual deepening of the Aleutian Low initiated the changes in the physical state of the ocean (Hare \& Mantua, 2000; Miller et al., 1994; Miller \& Schneider, 2000; Trenberth \& Hurrell, 1994).
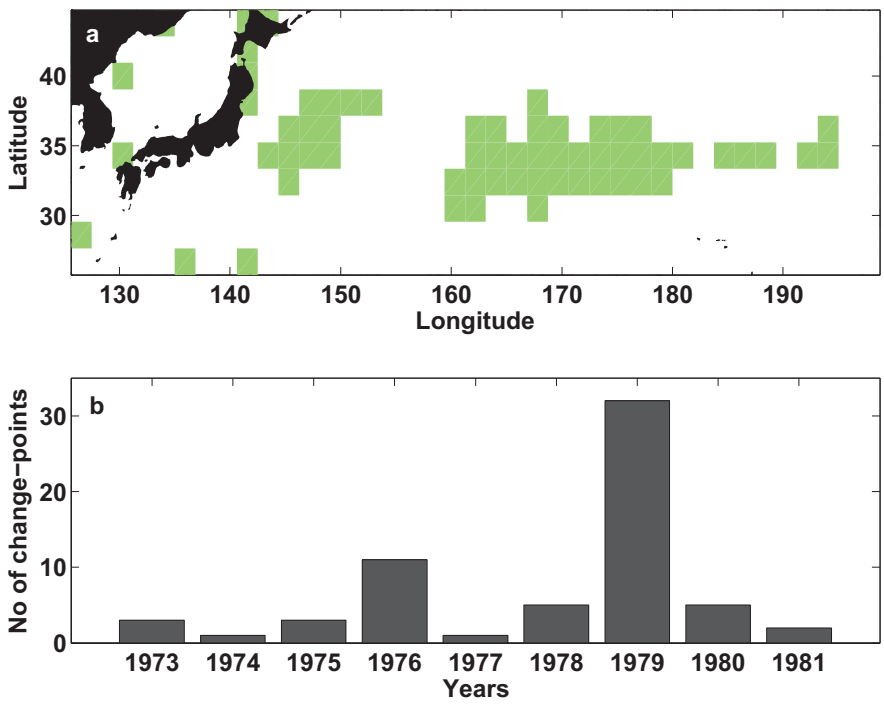

Figure 5. (a) Pixel-wise change-point analysis for the net heat flux in the Kuroshio Extension region. Areas where change-points are detected are colored and white areas indicate that no shift was detected. In all cases, at most one change-point is detected. (b) Histogram of the number of pixels with a changepoint detected in the late 1970 s and early 1980 s.
The dynamical proxies also revealed an extreme North Pacific High, which occurred most frequently during summer time (Figures $1 \mathrm{e}$ and $2 e)$. Indeed, the strongest high-pressure center of the North Pacific High is formed during summer (Kenyon, 1999). Similarly, North Pacific atmospheric blocking patterns defined as strong high pressures splitting the westerly flow into two branches were observed in this analysis during spring and autumn seasons. However, previous work showed that these atmospheric blocking patterns have strongest intensity in winter and spring time (Barriopedro et al., 2006; Fei et al., 2002). Further, atmospheric patterns that are formed during summer were found to be more persistent in comparison to the winter atmospheric conditions (Figures 2a and 2e). This seasonal variation is consistent with the increased frequency of short-lived (5-10 days) SLP patterns in winter compared to summer (Johnson \& Feldstein, 2010). Nevertheless, the extreme phases of the North Pacific High and the atmospheric blocking patterns did not appear in the results during the years of interest, centered on 1977. This suggests that the occurrence of these patterns did not take significant part in the triggering mechanisms of the late 1970 s regime shift.

The dominant EOF for the net heat flux and the associated changepoint analysis, highlight the importance of the Kuroshio Extension 


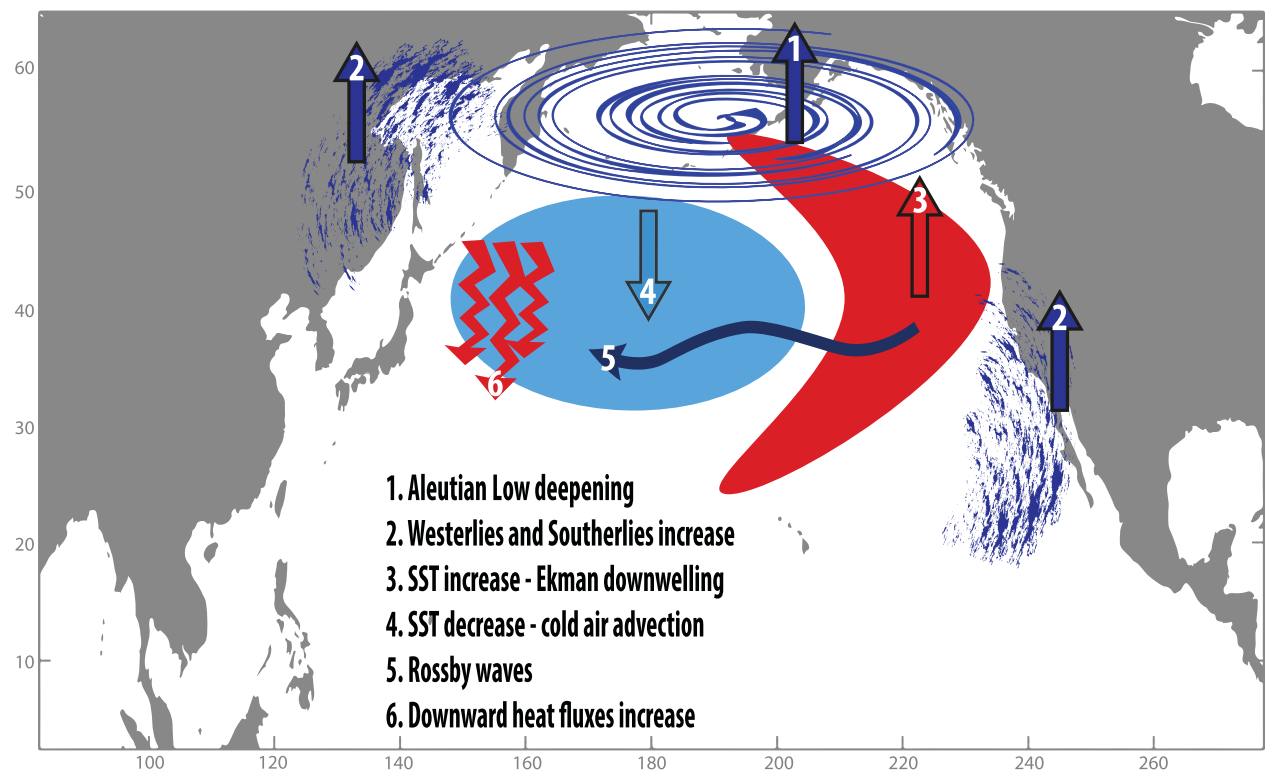

Figure 6. Schematic of the mechanism by which the deep Aleutian Low triggers increases in the wind strength from the west, causing variations in the sea surface temperature, sea surface height, and net heat fluxes.

region for the regional air-sea interaction processes (Figure 4). The results demonstrate a pronounced shift from negative to positive net heat flux in 1979 (Figure 4b), i.e., a shift from heat flux out of the ocean to the atmosphere, to the opposite scenario. Further, change-point analysis performed on winter net heat flux observations also revealed abrupt changes in the Kuroshio Extension region centered on 1977 (Figure 4c). Both analyses highlight the area of major air-sea heat exchange over the Kuroshio Extension region, even though a deep Aleutian Low would have prominent effects across the whole North Pacific. The Kuroshio Extension undergoes large decadal fluctuations mainly controlled by the Aleutian Low (Qiu et al., 2016) and responds to basin-scale changes in wind forcing and sea surface height with a lag of 2-4 years (Ceballos et al., 2009; Révelard et al., 2016). Both the transport and position of the Kuroshio current are affected by wind stress changes related to atmospheric patterns (e.g., the Aleutian Low) and the PDO in the eastern North Pacific through the propagation of Rossby waves and Ekman currents (Nonaka et al., 2005; Qiu, 2002). A deepening in the Aleutian Low (positive PDO) increases the westerlies and causes anomalous positive wind stress curl in the central North Pacific (Qiu et al., 2016), which enhances the southward Ekman drift (Seager et al., 2001). This produces negative sea surface height anomalies in the central region that propagate into the Kuroshio Extension region through Rossby waves (Qiu et al., 2016) and weakens the Kuroshio Extension jet (Qiu \& Chen, 2005). This process causes lagged responses of the SST of approximately 3-4 years in the western region (Sasaki et al., 2013), destabilizing the dynamical state of the Kuroshio Extension system (Qiu et al., 2016). SST variability in the region generates anomalous heat fluxes (Révelard et al., 2016), resulting in an area of maximum ocean-atmosphere heat exchange affecting the conditions of the whole North Pacific (Qiu et al., 2007, 2014). The reverse holds for a positive wind stress curl and negative PDO. This mechanism is presented schematically in Figure 6.

The main heat flux pattern revealed using our new approach on a long time series (1948 to present) captures $22 \%$ of the variance. Nevertheless, this pattern has been previously associated with variability in the dynamic state of the oceanic gyre and consequent atmospheric changes in response to oceanic forcing from the Kuroshio region (Qiu et al., 2014; Schneider et al., 2002; Schneider \& Miller, 2001). Our results are also consistent with a modeling study that provided insight into the maintenance processes of the altered oceanic conditions during the regime shift (Miller et al., 1994), which suggested that the conditions responsible for the 1976-1977 shift were established by extended changes in the air-sea fluxes, specifically by strong cooling of the Mid-Pacific region and warming into the California coastal areas. Miller et al. (1994) also suggested that long-term changes in the heat budget in the Mid-Pacific region maintained the unusual oceanic conditions. Although most studies have focused on the SST of the Kuroshio Extension, Kelly (2004) suggested that the heat content in the ocean surface better represents the air-sea interactions of the area. 
Among the heat budget terms, i.e., heat advection, mixing, and SST, surface net heat flux is the most anomalous forcing term, being four times larger than the others in the California Current region and two times larger in the Mid-Pacific (Miller et al., 1994). In addition, our results are also in agreement with the hypothesis that the decadal variability of the dynamical state of the Kuroshio Extension jet is associated with PDO variability originating in the eastern North Pacific (Qiu, 2003; Qiu et al., 2016). A rapid transition of the PDO index from negative to positive phase has been previously detected, occurring simultaneously with shifts in physical parameters in the North Pacific (Beaulieu et al., 2016; Mantua et al., 1997; Newman et al., 2016). At the same time, a shift of the North Pacific Gyre Oscillation (NPGO) index has been noted with reverse polarity to the PDO (Di Lorenzo et al., 2008; Litzow \& Mueter, 2014), even though later analyses could not demonstrate the significance of the abrupt shift in the NPGO index (Beaulieu et al., 2016). Additionally, ENSO variability in the tropical North Pacific affects the climate variability of the North Pacific region (Di Lorenzo et al., 2010) via the atmospheric bridge, leading to SST and circulation changes through atmospheric teleconnections, including changes in wind, humidity, and cloudiness (Alexander et al., 2004; Graham, 1994; Newman et al., 2016).

To conclude, we present a new approach to investigate marine regime shifts by combining dynamical proxies and statistical analyses, which may be useful in future studies to monitor and predict sudden changes due to extreme events. We use this analysis to show that an extreme atmospheric event occurred in winter 1976-1977 and contributed to the triggering of the major regime shift in the North Pacific. The intensification of the Aleutian Low atmospheric pattern has prominent effects on the regional winds, the SST, sea surface height as well as the heat fluxes of the whole North Pacific. Links from the western to the eastern basin, specifically the propagation of changes due to PDO variability through Rossby waves affecting the Kuroshio Extension jet, have been previously shown (Mantua \& Hare, 2002; Qiu et al., 2016, 2007; Schneider \& Cornuelle, 2005). The response of the extreme Aleutian Low in winter 1976-1977 is detected mainly in the heat fluxes of the Kuroshio Extension. Increasing atmospheric extreme events and the oceans' response may be responsible for more frequent regime shifts in the future and should be the focus of future studies.

\section{Acknowledgments}

The authors are grateful to the NOAA for providing the NCEP/NCAR reanalysis data set used here. The data can be found at the following URL https://www.esrl.noaa.gov/psd/data/ gridded/data.ncep.reanalysis.html. K.G. and C.B. are supported by a Marie Curie FP7 Reintegration Grants within the Seventh European Community Framework (project 631466-TROPHYZ). D.F. was supported by ERC grant 338965.

\section{References}

Akaike, H. (1973). Information theory and an extension of the maximum likelihood principle. In Petrov, B. N. \& Csaki, F. (Eds.), Proceedings of the 2nd international symposium on information theory (pp. 267-281). Budapest: Akademiai Kiado.

Alexander, M. A., Lau, N.-C., \& Scott, J. D. (2004). Broadening the atmospheric bridge paradigm: ENSO teleconnections to the Tropical West Pacific-Indian Oceans over the seasonal cycle and to the North Pacific in summer. In Wang, C., Xie, S. \& Carton, J. (Eds.), Earth's climate: The ocean-atmosphere interaction (Vol. 147, pp. 85-104). Washington, DC: American Geophysical Union. http://doi.org/10.1029/ 147GM05

Anderson, P. J., \& Piatt, J. F. (1999). Community reorganization in the Gulf of Alaska following ocean climate regime shift. Marine Ecology Progress Series, 189, 117-123. http://doi.org/10.3354/meps189117

Barriopedro, D., García-Herrera, R., Lupo, A. R., \& Hernández, E. (2006). A climatology of Northern Hemisphere blocking. Journal of Climate, 19, 1042-1063. http://doi.org/10.1175/JCLI3678.1

Beamish, R. J., Benson, A. J., Sweeting, R. M., \& Neville, C. M. (2004). Regimes and the history of the major fisheries off Canada's west coast. Progress in Oceanography, 60, 355-385. http://doi.org/10.1016/j.pocean.2004.02.009

Beaulieu, C., Chen, J., \& Sarmiento, J. L. (2012). Change-point analysis as a tool to detect abrupt climate variations. Philosophical Transactions of the Royal Society A, 370, 1228-1249. http://doi.org/10.1098/rsta.2011.0383

Beaulieu, C., Cole, H., Henson, S., Yool, A., Anderson, T. R., De Mora, L., et al. (2016). Marine regime shifts in ocean biogeochemical models: A case study in the Gulf of Alaska. Biogeosciences, 13, 4533-4553. http://doi.org/10.5194/bg-13-4533-2016

Ceballos, L. I., Di Lorenzo, E., Hoyos, C. D., Schneider, N., \& Taguchi, B. (2009). North Pacific gyre oscillation synchronizes climate fluctuations in the eastern and western boundary systems. Journal of Climate, 22, 5163-5174. http://doi.org/10.1175/2009JCLI2848.1

Chavez, F. P., Ryan, J., Lluch-Cota, S. E., \& Ñiquen, M. C. (2003). From anchovies to sardines and back: Multidecadal change in the Pacific Ocean. Science, 299, 217-221. http://doi.org/10.1126/science.1075880

Conversi, A., Dakos, V., Ling, S., Ga, A., Folke, C., Mumby, P. J., et al. (2015). A holistic view of marine regime shifts. Philosophical Transactions of the Royal Society B, 370, 20130279. http://doi.org/10.1098/rstb.2013.0279

Cury, P., \& Shannon, L. (2004). Regime shifts in upwelling ecosystems: Observed changes and possible mechanisms in the northern and southern Benguela. Progress in Oceanography, 60, 223-243. http://doi.org/10.1016/j.pocean.2004.02.007

Deser, C., Phillips, A. S., \& Hurrell, J. W. (2004). Pacific interdecadal climate variability: Linkages between the Tropics and the North Pacific during Boreal Winter since 1900. Journal of Climate, 17, 3109-3124. http://doi.org/10.1175/1520-0442(2004)017<0877:TEONAS>2.0. $\mathrm{CO} ; 2$

deYoung, B., Barange, M., Beaugrand, G., Harris, R., Perry, R. I., Scheffer, M., et al. (2008). Regime shifts in marine ecosystems: Detection, prediction and management. Trends in Ecology \& Evolution, 23, 402-409. http://doi.org/10.1016/j.tree.2008.03.008

Di Lorenzo, E., Cobb, K. M., Furtado, J. C., Schneider, N., Anderson, B. T., Bracco, A., et al. (2010). Central Pacific El Niño and decadal climate change in the North Pacific Ocean. Nature Geoscience, 3, 762-765. http://doi.org/10.1038/ngeo984

Di Lorenzo, E., \& Ohman, M. D. (2013). A double-integration hypothesis to explain ocean ecosystem response to climate forcing. Proceedings of the National Academy of Sciences of the Unites States of America, 110, 2496-2499. http://doi.org/10.1073/pnas.1218022110

Di Lorenzo, E., Schneider, N., Cobb, K. M., Franks, P. J. S., Chhak, K., Miller, A. J., et al. (2008). North Pacific Gyre Oscillation links ocean climate and ecosystem change. Geophysical Research Letters, 35, L08607. http://doi.org/10.1029/2007GL032838 
Faranda, D., Lucarini, V., \& Turchetti, G. (2011). Numerical convergence of the block-maxima approach to the generalized extreme value distribution. Journal of Statistical Physics, 145, 1156-1180. http://doi.org/10.1007/s10955-011-0234-7

Faranda, D., Messori, G., \& Yiou, P. (2017). Dynamical proxies of North Atlantic predictability and extremes. Scientific Reports, 7, 41278. http://doi.org/10.1038/srep41278

Fei, H., Faxiu, Z., \& Xiaodan, Q. (2002). Interannual and decadal variability of the north pacific blocking and its relationship to SST, teleconnection and storm tracks. Advances in Atmospheric Sciences, 19, 807-820. http://doi.org/10.1007/s00376-002-0046-4

Graham, N. E. (1994). Decadal-scale climate variability in the tropical and North Pacific during the 1970s and 1980s: Observations and model results. Climate Dynamics, 10, 135-162. http://doi.org/10.1007/BF00210626

Hare, S. R., \& Mantua, N. J. (2000). Empirical evidence for North Pacific regime shifts in 1977 and 1989. Progress in Oceanography, 47, 103145. http://doi.org/10.1016/S0079-6611(00)00033-1

Hsieh, C., Glaser, S. M., Lucas, A. J., \& Sugihara, G. (2005). Distinguishing random environmental fluctuations from ecological catastrophes for the North Pacific Ocean. Nature, 435(7040), 336-340. http://doi.org/10.1038/nature03553

Hsieh, C., \& Ohman, M. D. (2006). Biological responses to environmental forcing: The linear tracking window hypothesis. Ecology, 87, 19321938. http://doi.org/10.1890/0012-9658(2006)87[1932:BRTEFT]2.0.CO

Hurrell, J. W. \& National Center for Atmospheric Research Staff (2016). The Climate Data Guide: North Pacific (NP) Index by Trenberth and Hurrell; monthly and winter. Retrieved from https://climatedataguide.ucar.edu/climate-data/north-pacific-np-index-trenberth-and-hurrellmonthly-and-winter, last modified 27 Oct 2017

Johnson, N. C., \& Feldstein, S. B. (2010). The continuum of North Pacific sea level pressure patterns: Intraseasonal, interannual, and interdecadal variability. Journal of Climate, 23, 851-867. http://doi.org/10.1175/2009JCLI3099.1

Kalnay, E., Kanamitsu, M., Kistler, R., Collins, W., Deaven, D., Gandin, L., et al. (1996). The NCEP/NCAR 40-year reanalysis project. Bulletin of the American Meteorological Society, 77, 437-471. http://doi.org/10.1175/1520-0477(1996)077<0437:TNYRP $>2.0 . C O ; 2$

Kelly, K. A. (2004). The relationship between oceanic heat transport and surface fluxes in the Western North Pacific: 1970-2000. Journal of Climate, 17, 573-588. http://doi.org/10.1175/1520-0442

Kenyon, K. E. (1999). North Pacific high: An hypothesis. Atmospheric Research, 51, 15-34. http://doi.org/10.1016/S0169-8095(98)00110-0

Killick, R., Beaulieu, C., Taylor, S. \& Hullait H. (2018). CRAN - Package "EnvCpt." Retrieved from https://cran.r-project.org/web/packages/ EnvCpt/index.html

Latif, M., \& Barnett, T. (1994). Causes of decadal climate variability over the North Pacific and North America. Science, 266, 634-637. http:// doi.org/10.1126/science.266.5185.634

Lees, K., Pitois, S., Scott, C., Frid, C., \& Mackinson, S. (2006). Characterizing regime shifts in the marine environment. Fish and Fisheries, 7 , 104-127. http://doi.org/10.1111/j.1467-2979.2006.00215.x

Litzow, M. A., \& Mueter, F. J. (2014). Assessing the ecological importance of climate regime shifts: An approach from the North Pacific Ocean. Progress in Oceanography, 120, 110-119. http://doi.org/10.1016/j.pocean.2013.08.003

Lucarini, V., Faranda, D., Freitas, A. C. M., Freitas, J. M., Kuna, T., Holland, M., et al. (2016). Extremes and recurrence in dynamical systems. New York, NY: Wiley. http://arxiv.org/abs/1605.07006

Mantua, N. J., \& Hare, S. R. (2002). The Pacific decadal oscillation. Journal of Oceanography, 58, 35-44. http://doi.org/10.1023/ A:1015820616384

Mantua, N. J., Hare, S. R., Zhang, Y., Wallace, J. M., \& Francis, R. C. (1997). A Pacific interdecadal climate oscillation with impacts on salmon production. Bulletin of the American Meteorological Society, 78, 1069-1079. http://doi.org/10.1175/1520-0477

McGowan, J. A. (1998). Climate-ocean variability and ecosystem response in the Northeast Pacific. Science, 281, 210-217. http://doi.org/10. 1126/science.281.5374.210

Miller, A., Cayan, D., Barnett, T., Graham, N., \& Oberhuber, J. (1994). The 1976-77 climate shift of the Pacific Ocean. Oceanography, 7, 21-26. http://doi.org/10.5670/oceanog.1994.11

Miller, A. J., \& Schneider, N. (2000). Interdecadal climate regime dynamics in the North Pacific Ocean: Theories, observations and ecosystem impacts. Progress in Oceanography, 47, 355-379. http://doi.org/10.1016/S0079-6611(00)00044-6

Minobe, S. (1997). A 50-70 year climatic oscillation over the North Pacific and North America. Geophysical Research Letters, 24, 683-686.

Newman, M., Alexander, M. A., Ault, T. R., Cobb, K. M., Deser, C., Di Lorenzo, E., et al. (2016). The Pacific Decadal Oscillation, revisited. Journal of Climate, 29, 4399-4427. http://doi.org/10.1175/JCLI-D-15-0508.1

Nitta, T., \& Yamada, S. (1989). Recent warming of tropical sea surface temperature and its relationship to the northern hemisphere circulation. Journal of the Meteorological Society of Japan, 67, 375-383. http://doi.org/10.2151/jmsj1965.67.3_375

Nonaka, M., Nakamura, H., Tanimoto, Y., Kagimoto, T., \& Sasaki, H. (2005). Decadal variability in the Kuroshio-Oyashio Extension Simulated in an Eddy-Resolving OGCM. Journal of Climate, 19, 1970-1989. http://doi.org/10.1175/JCLI3793.1

Overland, J. E., Percival, D. B., \& Mofjeld, H. O. (2006). Regime shifts and red noise in the North Pacific. Deep Sea Research Part I, 53, 582588. http://doi.org/10.1016/j.dsr.2005.12.011

Pickands, J. (1975). Statistical inference using extreme order statistics. Annals of Statistics, 3, 119-131. http://doi.org/10.1214/aos/1176343003

Pierce, D. W. (2001). Distinguishing coupled ocean-atmosphere interactions from background noise in the North Pacific. Progress in Oceanography, 49(1-4), 331-352. http://doi.org/10.1016/S0079-6611(01)00029-5

Qiu, B. (2002). Large-scale variability in the midlatitude subtropical and subpolar North Pacific Ocean: Observations and causes. Journal of Physical Oceanography, 32, 353-375. https://doi.org/10.1175/1520-0485(2002)032<0353:LSVITM > 2.0.CO;2

Qiu, B. (2003). Kuroshio extension variability and forcing of the pacific decadal oscillations: Responses and potential feedback. Journal of Physical Oceanography, 33, 2465-2482. https://doi.org/10.1175/2459.1

Qiu, B., \& Chen, S. (2005). Variability of the Kuroshio Extension Jet, recirculation gyre, and mesoscale eddies on decadal time scales. Journal of Physical Oceanography, 35, 2090-2103. http://doi.org/10.1175/JPO2696.1

Qiu, B., Chen, S., \& Schneider, N. (2016). Inter-decadal modulations in the dynamical state of the Kuroshio Extension System: 1905-2015 (CLIVAR Exchanges, No. 69, pp. 6-9). Southampton, UK: CLIVAR Project Office.

Qiu, B., Chen, S., Schneider, N., \& Taguchi, B. (2014). A coupled decadal prediction of the dynamic state of the Kuroshio extension system. Journal of Climate, 27, 1751-1764. http://doi.org/10.1175/JCLI-D-13-00318.1

Qiu, B., Schneider, N., \& Chen, S. (2007). Coupled decadal variability in the North Pacific: An observationally constrained idealized model. Journal of Climate, 20, 3602-3620. http://doi.org/10.1175/JCLI4190.1

Révelard, A., Frankignoul, C., Sennéchael, N., Kwon, Y. O., \& Qiu, B. (2016). Influence of the decadal variability of the Kuroshio Extension on the atmospheric circulation in the cold season. Journal of Climate, 29, 2123-2144. http://doi.org/10.1175/JCLI-D-15-0511.1

Rienecker, M. M., \& Ehret, L. L. (1988). Wind stress curl variability over the North Pacific from the comprehensive ocean-atmosphere data set. Journal of Geophysical Research, 93, 5069-5077. http://doi.org/10.1029/JC093iC05p05069 
Rudnick, D. L., \& Davis, R. E. (2003). Red noise and regime shifts. Deep-Sea Research Part l, 50, 691-699. http://doi.org/10.1016/S09670637(03)00053-0

Sasaki, Y. N., Minobe, S., \& Schneider, N. (2013). Decadal response of the Kuroshio Extension Jet to Rossby waves: Observation and thin-jet theory*. Journal of Physical Oceanography, 43, 442-456. http://doi.org/10.1175/JPO-D-12-096.1

Schneider, N., \& Cornuelle, B. D. (2005). The forcing of the Pacific Decadal Oscillation. Journal of Climate, 18, 4355-4373. http://doi.org/10. $1175 /$ JCLI3527.1

Schneider, N., \& Miller, A. J. (2001). Predicting Western North Pacific Ocean Climate. Journal of Climate, 14, 3997-4002. http://doi.org/10. 1175/1520-0442(2001)014<3997:PWNPOC $>2.0 . C O ; 2$

Schneider, N., Miller, A. J., \& Pierce, D. W. (2002). Anatomy of North Pacific decadal variability. Journal of Climate, 15, 586-605. http://doi. org/10.1175/1520-0442

Schwing, F. B., Mendelssohn, R., Bograd, S. J., Overland, J. E., Wang, M., \& Ito, S. (2010). Climate change, teleconnection patterns, and regional processes forcing marine populations in the Pacific. Journal of Marine Systems, 79, 245-257. http://doi.org/10.1016/j.jmarsys. 2008.11 .027

Seager, R., Kushnir, Y., Naik, N. H., Cane, M. A., \& Miller, J. (2001). Wind-driven shifts in the latitude of the Kuroshio-Oyashio Extension and generation of SST anomalies on decadal timescales*. Journal of Climate, 14, 4249-4265. https://doi.org/10.1175/15200442(2001)014<4249:WDSITL>2.0.CO;2

Süveges, M. (2007). Likelihood estimation of the extremal index. Extremes, 10, 41-55. http://doi.org/10.1007/s10687-007-0034-2

Trenberth, K. E., \& Hurrell, J. W. (1994). Decadal atmosphere-ocean variations in the Pacific. Climate Dynamics, 9, 303-319. http://doi.org/10. 1007/BF00204745

Wang, P., Wang, J. X. L., Zhi, H., Wang, Y., \& Sun, X. (2012). Circulation indices of the Aleutian low pressure system: Definitions and relationships to climate anomalies in the northern hemisphere. Advances in Atmospheric Sciences, 29, 1111-1118. http://doi.org/10.1007/ s00376-012-1196-7

Yasunaka, S. \& Hanawa, K. (2002). Regime shifts found in the Northern Hemisphere SST field. Journal of Meteoroogical Society of Japan, 80 , 119-135. https://doi.org/10.2151/jmsj.80.119

Yatsu, A., Aydin, K. Y., King, J. R., McFarlane, G. A., Chiba, S., Tadokoro, K., et al. (2008). Elucidating dynamic responses of North Pacific fish populations to climatic forcing: Influence of life-history strategy. Progress in Oceanography, 77, 252-268. http://doi.org/10.1016/j. pocean.2008.03.009

Zhang, Y., Wallace, J. M., \& Battisti, D. S. (1997). ENSO-like interdecadal variability: 1900-93. Journal of Climate, 10, 1004-1020. http://doi. org/10.1175/1520-0442(1997)010<1004:ELIV >2.0.CO;2 